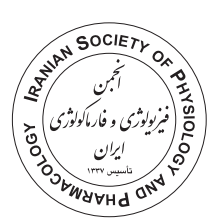

\title{
Topical formulation of tranilast improves hypertrophic scar in a rat model
}

\author{
Sara Darakhshan ${ }^{1}$, Fereshteh Bagheri' ${ }^{1}$, Seyran Kakabaraei², Reza Tahvilian ${ }^{1 *}$ (iD
}

1. Pharmaceutical Sciences Research Center, Health Institute, Kermanshah University of Medical Sciences, Kermanshah, Iran

2. Department of Anatomical Sciences \& Cell Biology, Kermanshah University of Medical Sciences, Kermanshah, Iran

\begin{abstract}
Introduction: Hypertrophic scars are dermal complication that may lead to considerable morbidity. There is an intense medical need for novel therapies for this disease. Tranilast is an anti-allergic agent that clinically used for the treatment of keloids and hypertrophic scars. In this study, we aimed to evaluate the effect of tranilast $0.5 \%$ topical formulation on hypertrophic scars resulted by burn injury in rats.

Methods: Burn wounds were inflicted on the skin area of the backs of all rats, following that the scars are created, treatment started and continued for 28 days. Animals were divided into two groups $(\mathrm{n}=8)$ : the control scar group, which received a placebo and the treatment group that received $0.5 \%$ tranilast gel. After this period, skin biopsies were collected from each group for the following analyses. The tissue samples were analyzed by hematoxylin-eosin, Masson's trichrome staining and qRT-PCR.

Results: Histologically, topical tranilast reduced hypertrophic scar signs as compared to placebo. Tranilast treatment also resulted in a reduction in type I and III collagen, transforming growth factor-beta1, Smad2 and vascular endothelial growth factor, and increased Smad7 mRNA expression in the skin scar site.

Conclusion: These findings showed that the $0.5 \%$ tranilast topical gel could be effective in the treatment of hypertrophic scars in a rat experiment.
\end{abstract} Keywords: Tranilast Hypertrophic scar

Wound healing

Topical formulation

\section{Introduction}

Scarring is a significant medical burden, as treatments for scars impose an expensive cost to the health care system (Marshall et al., 2018). A total of 100 million patients develop scars in the western countries per annum as a result of surgical procedures, traumas and burns (Widgerow and Chait, 2011). As well as the several psychological problems (Martin et al., 2003), scarring due to a burn injury results in loss of function, restriction of movement ability, discomfort, pain and itching (Van Loey et al., 2008; Unahabhokha et al., 2015). Treatment of hypertrophic burn scars is challenging and often is not satisfactory despite the many therapeutic approaches currently are available for hypertrophic scars, such as laser treatment, silicone gel, intralesional or topical corticosteroids and chemotherapeutic agents (Brett and Duscher, 2019). These therapies have complex delivery routes, need to a long-term period of use, as well as significant side effects (Nicholas and Yeung, 2017). Thus, a

\footnotetext{
* Corresponding author: Reza Tahvilian, rtahvilian@kums.ac.ir

Received 5 August 2020; Revised from 30 November 2020; Accepted 17 December 2020

Citation: Darakhshan S, Bagheri F, Kakabaraei S, Tahvilian R. Topical formulation of tranilast improves hypertrophic scar in a rat model. Physiology and Pharmacology 2021; 25: 242-250. http://dx.doi.org/10.52547/ppj.25.3.242
} 
treatment option that is simple to use and cost-effective, also has minimal side effects would be more beneficial for both clinicians and patients.

Tranilast drug, N-(3',4'-dimethoxycinnamoyl) anthranilic acid, is used to treatment of various inflammatory conditions such as atypical dermatitis, keloids and hypertrophic scars (Darakhshan and Pour, 2015). In general, tranilast drug was administrated orally (Goto et al., 1991; Darakhshan and Pour, 2015); however, other formulations of the drug are also improved such as ophthalmic solution (Kogure et al., 1993) and nasal spray (Sato et al., 2015). Kohavi et al. (2017) also examined a dermal liposomal formulation of tranilast. In this study, the efficacy and safety of an $8 \%$ liposomal gel of tranilast evaluated in new post-cesarean section surgical wounds for a 9 months-period. Results showed women treated with tranilast were significantly more satisfied compared with placebo. Regard to skin problems, topical formulations seem that to be easier for use and more in effect than oral administration.

The hydroxypropyl methylcellulose (HPMC) and carboxymethyl cellulose (CMC) are derivatives of cellulose with a wide range of physicochemical properties, forming suitable hydrogel for dermatological applications. Due to their biocompatibility and biodegradability, also beneficial properties for skin tissue, both HPMC and $\mathrm{CMC}$ are widely applied in topical controlled-release forms (Vanti et al., 2020). In this study, therefore, tranilast was loaded into a HPMC/CMC-based hydrogel. Therefore, our animal study was designed to evaluate the efficacy of a topical formulation of tranilast to improve the hypertrophic scars.

\section{Materials and methods}

\section{Formulation tranilast gel}

Tranilast $0.5 \%$ gel was provided by the addition of $2 \mathrm{~g}$ HPMC to $100 \mathrm{ml}$ water $\left(70^{\circ} \mathrm{C}\right)$ under constant stirring. Then, $0.5 \mathrm{~g}$ CMC slowly was added under mixing until complete gel formation. Tranilast $0.5 \mathrm{~g}$ was dissolved into $2 \mathrm{ml}$ black seed oil (extracted from Nigella sativa) and transferred into the prepared gel. Ultimately, $1 \%$ of ascorbic acid was added as a preservative, then packed into aluminum tubes. The concentration in this study was chosen based on a $0.5 \%$ ophthalmic solution, which showed that can penetrate easily through the eye's surface (Kogure et al., 1993).

\section{Drug release analysis}

For analysis of drug release using Franz diffusion cell, $12 \mathrm{kDa}$ dialysis membrane was first activated in boiling distilled water for $45 \mathrm{~min}$. The membrane was then fixed between the donor and receptor sections. Twenty milligram of $0.5 \%$ tranilast gel was weighed and transferred into the donor compartment. The receptor section was filled with $50 \mathrm{ml}$ of phosphate buffer ( $\mathrm{pH} 5$ and 7.4). The receiver medium was maintained at $37^{\circ} \mathrm{C}$ using a circulating water bath and the acceptor section was magnetically stirred at $600 \mathrm{rpm}$ throughout the experiment. At different time points (5-420 min), $1 \mathrm{ml}$ aliquots were picked up through the sampling port and substituted immediately with an equal volume of fresh solution to maintain a constant volume of the receiving solution. The samples were then analyzed by spectrophotometric apparatus at $333 \mathrm{~nm}$ against an appropriate reference (Khiljee et al., 2010). Three replicates of each experiment were done. The results were plotted as a cumulative percentage of drug release versus time.

\section{Animals and hypertrophic scar formation}

Sixteen adult male Sprague-Dawley rats aged 2-3 months, weighing between 180-220g were maintained one per cage and under standard conditions. All animals were anesthetized with a mixture of $70 \mathrm{mg} / \mathrm{kg}$ ketamine and $10 \mathrm{mg} / \mathrm{kg}$ xylazine (both from Alfasan, Woerden, Holland) prior to the burn wound induction. The dorsal skin was shaved and the burn injury was created using a cylindrical metal device heated at $92^{\circ} \mathrm{C}$ for $30 \mathrm{~s}$ (a circular region with a $30-\mathrm{mm}$ diameter and $10-\mathrm{mm}$ thickness) (Cuttle et al., 2006). The wounds were not sealed or covered but were allowed to heal naturally. Animals were kept for about 4 weeks until the wounds healed. Most wounds were second-degree burns and developed contracted hypertrophic scars. After this time, animals were divided into two groups with eight rats per each: hypertrophic scar group, those were placebo and animals were treated with tranilast. Gels were topically administrated once and about $4 \mathrm{~g}$ daily for 28 days. On day 29, all rats were sacrificed and an about $2 \mathrm{~cm}^{2}$ section was obtained from each animal using surgical procedures. Upon burn wounding, at day 0 of scar and 28 days after the intervention, all animals were photographed. The study protocol was approved by the Ethics Committee of Kermanshah University of Medical Sciences (Ethical code 94279) and animal care was in accordance with the 
TABLE 1: Rat-specific primers used for qRT-PCR analysis.

\begin{tabular}{|c|c|c|}
\hline Gene & Sense/Antisense ( 5 ' to 3') & Product size $(\mathrm{bp})$ \\
\hline \multirow{2}{*}{ Collagen1a1 } & CCTACACTGTCCTTGTCGATG & \multirow{2}{*}{120} \\
\hline & TGTCCAGAGGTGCAATGTC & \\
\hline \multirow{2}{*}{ Collagen $3 a 1$} & CCTCCCAGAACATTACATACCAC & \multirow{2}{*}{194} \\
\hline & GACTGTCTTGCTCCATTCACCA & \\
\hline \multirow{2}{*}{$\operatorname{Tg} f b 1$} & CCTGAGTGGCTGTCTTTTGA & \multirow{2}{*}{124} \\
\hline & CGTGGAGTACATTATCTTTGCTG & \\
\hline \multirow{2}{*}{ Smad2 } & ACGGCTTTACAGATCCATCG & \multirow{2}{*}{142} \\
\hline & GCAAACACTTCCССАССТАTG & \\
\hline \multirow{2}{*}{ Smad7 } & AGGTCATCTTCAACAGCCG & \multirow{2}{*}{125} \\
\hline & CGACCGAAAGAGTTTTGCATG & \\
\hline \multirow{2}{*}{ Vegf-a } & TGAACTTTCTGCTCTCTTGGG & \multirow{2}{*}{105} \\
\hline & СTTTCTGCTCСССТTCTGTC & \\
\hline \multirow{2}{*}{$A c t b$} & САСТTTCTACAATGAGCTGCG & \multirow{2}{*}{148} \\
\hline & CTGGATGGCTACGTACATGG & \\
\hline
\end{tabular}

related guidelines.

\section{Histological examination}

The skin tissues of normal, placebo-treated and tranilast-treated groups were fixed in $10 \%$ buffered formalin for $72 \mathrm{~h}$. Paraffinized tissue blocks were prepared for sectioning at 6-8 $\mu \mathrm{m}$ thickness and the sections were stained with hematoxylin-eosin (H\&E) and Masson's trichrome (MT) staining. Slides were placed in a staining jar and deparaffinized by a series of absolute xylene for $10 \mathrm{~min}$ followed by $100 \%, 100 \%, 96 \%, 90 \%$ and $70 \%$ ethanol for 3 min of each step. Following rehydration, the slides were stained by hematoxylin and washed in running tap water for $2 \mathrm{~min}$. After that, slides were submerged into eosin for $2 \mathrm{~min}$ followed by washing in running tap water for $2 \mathrm{~min}$. Stained slides were dehydrated, cleared and mounted with resinous mounting medium. For MT staining, after deparaffinization and rehydration, sections were stained in hematoxylin (4min). After rinsing in tap water, the samples stained with eosin (10 min), later differentiated in 1\% phosphomolybdic acid solution (30min) and Fast Green (3min). Following rinsing in distilled water and a step in $1 \%$ acetic acid solution, dehydration through increasing concentrations of alcohol was done. Sections were cleared in xylene and mounted. Images were captured with a light microscope (Olympus $\mathrm{CH} 3$, Japan).

\section{$R N A$ isolation and $q R T-P C R$}

Full-thickness skin tissues from scarred rats treated by placebo or tranilast, and also from healthy rats were obtained and stored in liquid nitrogen until processed for RNA isolation. Total RNA was extracted from scar region treated with tranilast or placebo, and normal skin using a standard RNA extraction protocol (TRIzol reagent, Invitrogen, USA). RNA was reverse transcribed using PrimeScript First Strand cDNA Synthesis Kit (TaKaRa Bio Inc., Japan) and quantitative RT-PCR (qRT-PCR) was performed using SYBR Green Master Mix (TaKaRa Bio Inc., Japan) and Corbett Rotor-Gene 6000 thermocycler. The sequence of the primers and the length of the amplified fragments are shown in Table 1. Expression levels of target genes were normalized against beta-actin mRNA level as a housekeeping and the placebo group was expressed as 1 to indicate a precise fold-change.

\section{Statistical analysis}

Statistical analysis was performed using SPSS 19.0 software (SPSS Inc., USA) and data are presented as the mean \pm standard deviation (SD). The one-way analysis of variance (ANOVA) was used to evaluating the differences between groups and a value of $P<0.05$ was considered as significant.

\section{Results}

The measurement of drug release from a given dosage form is fundamental to drug product development. The specific technique employed is determined by the dosage form itself and the intended delivery route. For 


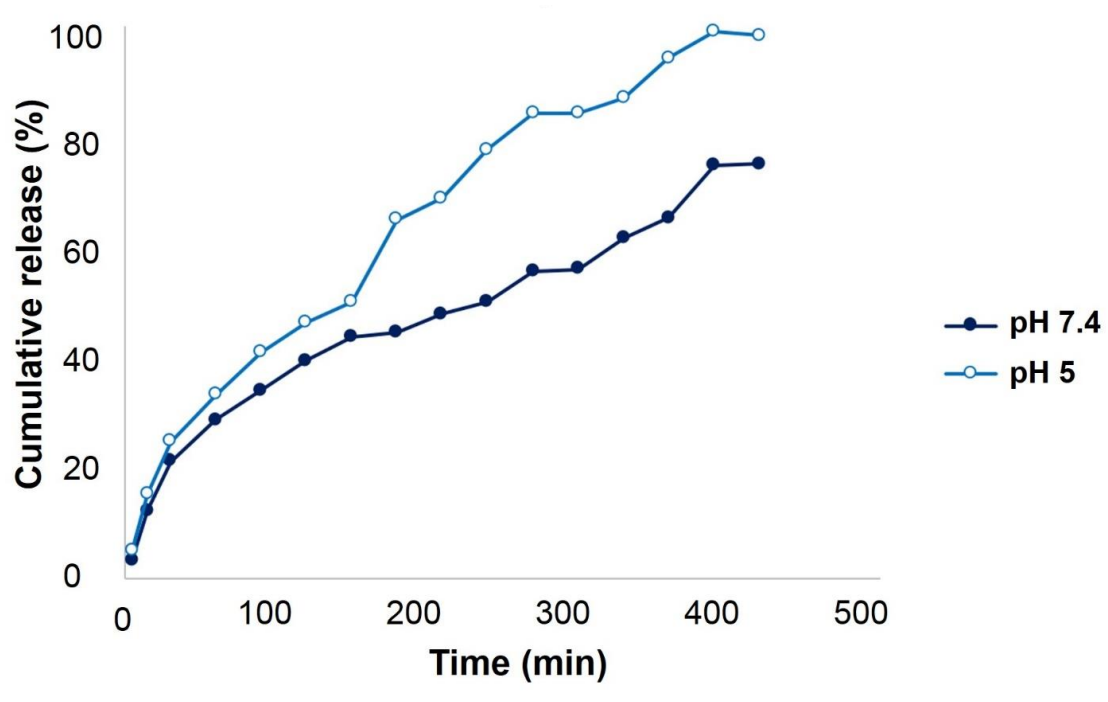

FIGURE 1. Tranilast releases from gel formulation effectively. Measurement of drug release from $0.5 \%$ tranilast topical formulation at $\mathrm{pH} 5$ and 7.4.

solid dosage forms, dissolution testing has been used frequently (Zhang and Yu, 2004). As shown in Figure 1 , tranilast gel had the appropriate dissolution rate and the sustained release at both tested pHs, 5 and 7.4. Especially, at the acidic conditions, tranilast gel demonstrated more performance compared with neutral $\mathrm{pH}$ value. During 420min incubation, drug release from gel reached about $98.96 \%$ and $75 \%$ at $\mathrm{pH} 5$ and $\mathrm{pH} 7.4$, respectively. It may be explicated by enhanced $\mathrm{pH}$ of medium and change of drug crystallinity in tranilast gel (Yang et al., 2014). Given that the pH of HPMC gel in an aqueous solution is around neutral, the dissociation of tranilast gel in dissolution media could enhance the solubility of tranilast as a weakly acidic drug. Furthermore, the hydrophilic nature of the HPMC/CMC polymer base presented better wettability of tranilast.

For modeling of scar formation, we burned the rats with a heated metal device. After a 28-days period, scars could be visualized on the wounded regions. Most wounds had acceptable scar formation and showed histologic evidence of hypertrophic scarring (Figure 2A). Photographs of the wound area, scar region and treated region with topical placebo or tranilast are shown in Figure 2A. The dermal layer in the skin of the burn scar site for placebo-treated group was markedly different from the corresponding layer in the normal skin. By H\&E staining we differentiated structures in the skin such as collagen fibers and hair follicles. In the tranilast-treated group, there were a number of prominent, actively growing hair follicles in the dermal layer, while in pla- cebo group we did not show regrowth of hair follicles (Figure 2B).

A hypertrophic scar is manifested by increased production of collagen in the skin. As shown in Figure 2C, the dermis layer of the placebo group thickened, and collagen fibers in dermis were dense and disorganized. However, the dermal thickness of scar site was reduced in animals treated with tranilast, the volume density of the collagen bundles decreased and the collagen organization improved compared to the placebo group (Figure 2C).

Figure 3 shows the results of gene expression at mRNA level using qRT-PCR for samples from placebo and tranilast groups after 28 days of treatment also normal skin group. The mRNA of type I collagen increased in the scarred site at day 28 compared to normal skin significantly $(P<0.001)$. By 28 days following tranilast treatment, type I collagen showed a decreased value compared to placebo, which was significant $(P=0.041)$. In the tranilast group, the expression of type III collagen was significantly lower than the placebo $(P<0.01)$. At the placebo-treated scar region, vascular endothelial growth factor (Vegf) mRNA was detected at a high level, the expression of its decreased at 28 days after treatment with tranilast $(P=0.008)$. We examined the expression of transforming growth factor-betal (Tgf-bl) and two its down-stream mediators, Smad 2 and Smad7. The Tgf- $\beta 1$ mRNA were faintly detected in normal skin tissue (Fig. $3)$; its expression was increased in the placebo group $(P<0.001)$; but treatment by tranilast caused to a mean- 


\section{A}
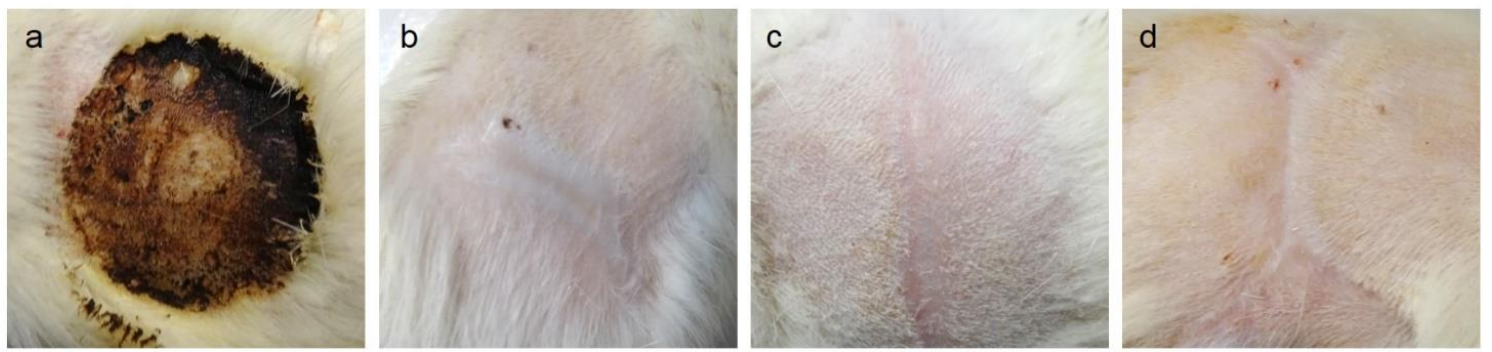

\section{B}
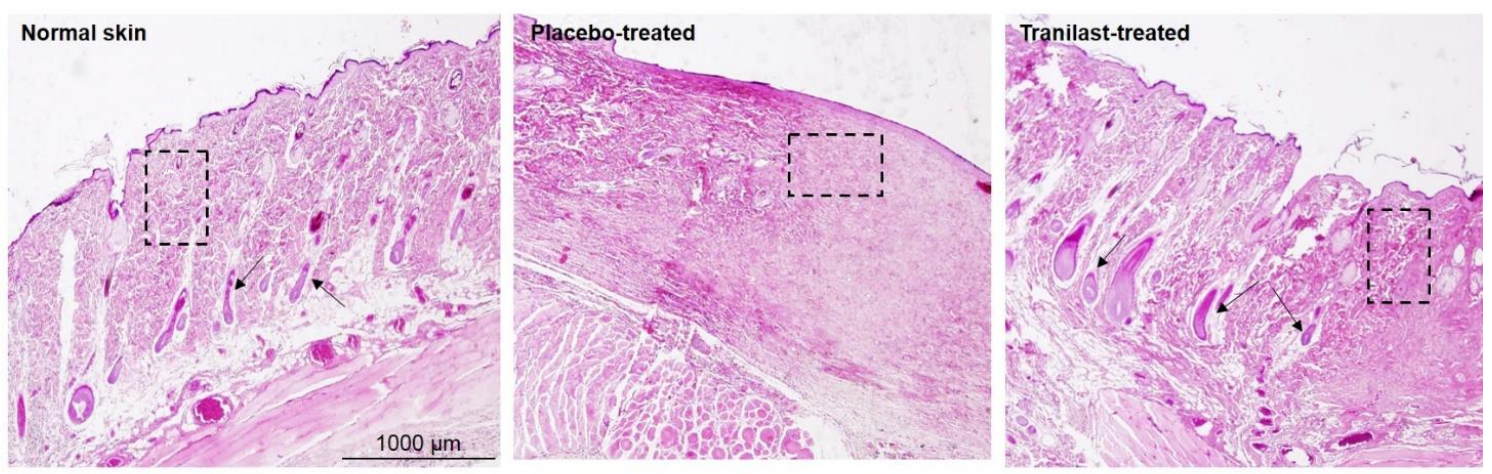

C
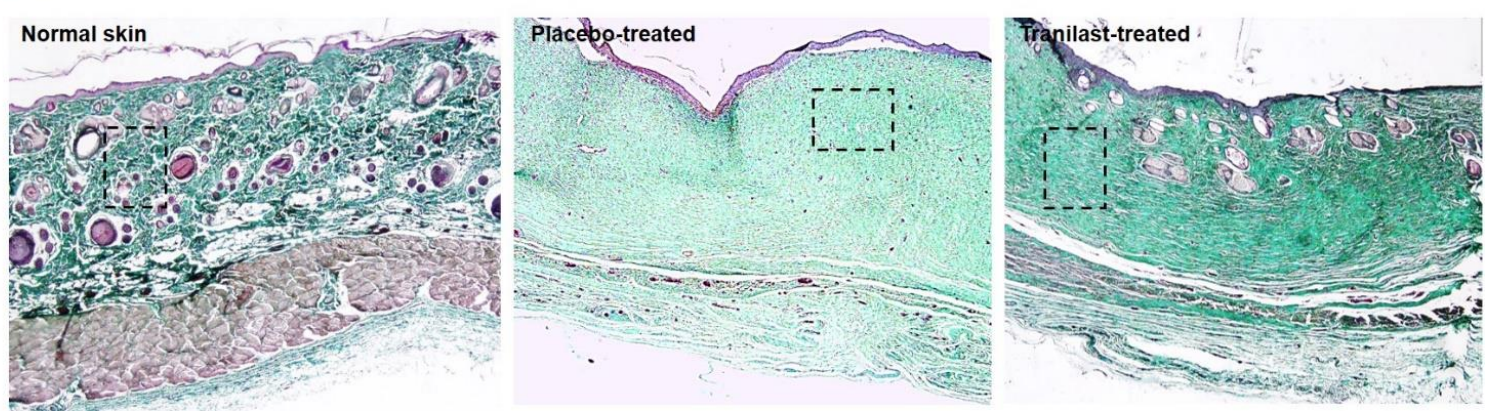

FIGURE 2. Topical formulation of tranilast improves hypertrophic scar in rats. A) a) circular region of the dorsal skin (with 30-mm diameter and 10-mm thickness) were burned using a heated cylindrical metal device; b) scar formation at day 28; c, d) after a 28-days period of treatment with topical tranilast or placebo. B) H\&E histological analysis of scarred skin received placebo or tranilast. C) Masson's trichrome staining of scarred skin received placebo or tranilast. The arrows indicate to hair follicles and the dashed rectangles indicate the distribution and density of collagen fibers in the skin tissue.

ingful reduction in its expression $(P<0.01)$. After 28 days of treatment, Smad 2 showed a significant decrease in tranilast group compared to the placebo $(P<0.001)$. However, on the 28 days after treatment with tranilast, Smad7 expression showed an increase in comparison to the placebo group, which was not significant.

\section{Discussion}

A major morbidity cause of skin burns is the development of burn scar contractures (Shpichka et al., 2019). The incidence rate of hypertrophic scarring is up to $91 \%$ following burn injury, hence most studies on scar treatment are focused on the burn scar (Monstrey et al., 2008). Hypertrophic scarring is caused by the progressive increase in collagen synthesis and excessive deposition of type I collagen, the main structural component of the extracellular matrix (ECM). Tranilast found that inhibits selectively the proliferation of fibroblasts and suppresses collagen synthesis and deposition in various conditions such as fibrotic disorders, keloids, hypertrophic scars, renal compliances and ocular diseases (Darakhshan and Pour, 2015). In this study, H\&E staining provided a qualitative assessment of morphological changes in skin tissue. Excessive deposition of 


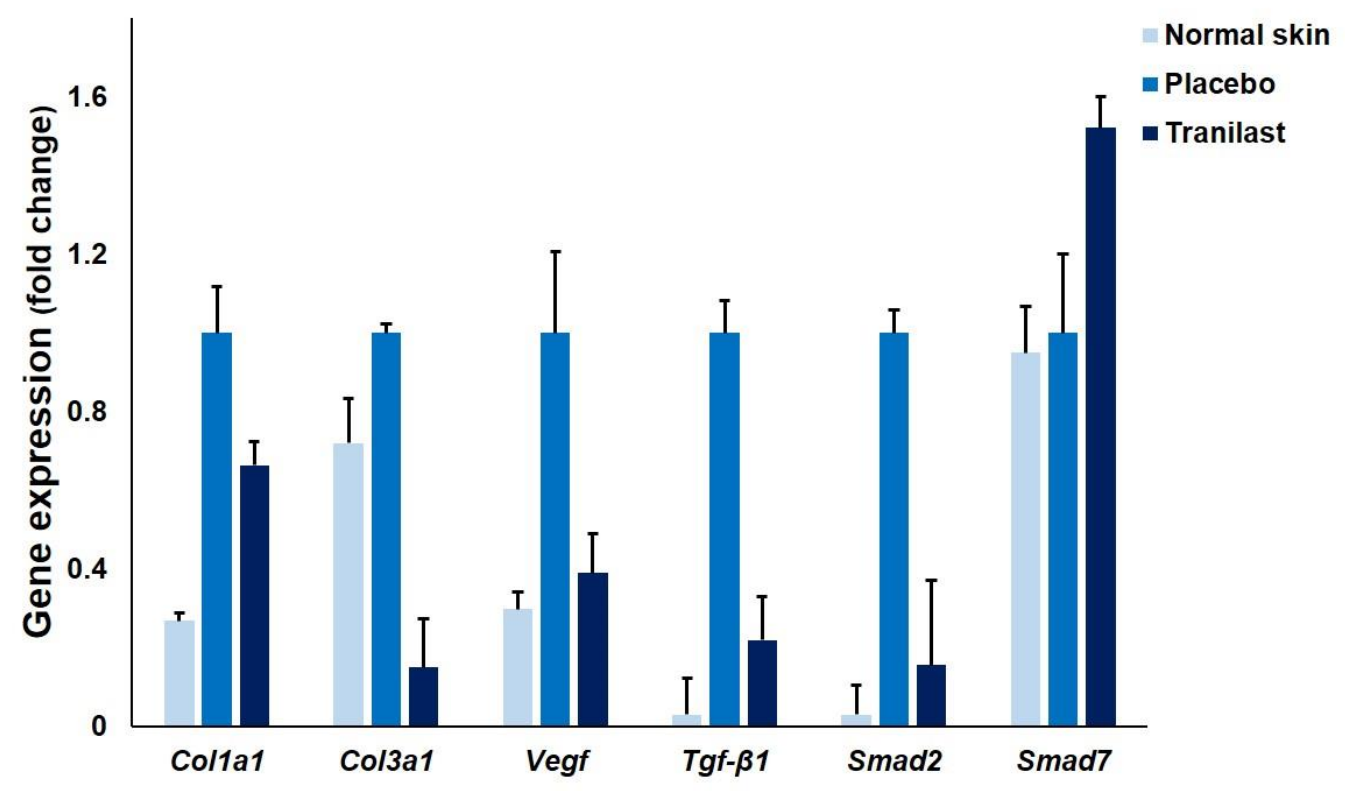

FIGURE 3. Topical $0.5 \%$ tranilast gel changes the expression of genes related to the hypertrophic skin scar towards improvement in rats after a 28-days treatment period. The target gene expression level was normalized to Actb and calibrated to the placebo group. All values represent mean \pm SD. $* \mathrm{P}<0.05, * * \mathrm{P}<0.01$ and $* * * \mathrm{P}<0.001$ vs. placebo.

collagen was recognizable in the scar region, while in tranilast-treated group collagen fibers were diminished and were closer to normal skin. MT staining showed a densely packed type I collagen networks at scar regions, while following a 28-days period of treatment by tranilast, the collagen bundles appeared in a more regular arrangement and collagen accumulation was decreased. Histopathological evaluations revealed the effect of topical tranilast in hypertrophic scar therapy as a remarkable resolver of the nodular arrangement of collagen. Moreover, results from qRT-PCR showed a significant reduction in type I collagen mRNA level in the tranilast-treated group compared to the placebo group.

The VEGF is involved in migration, proliferation and survival of endothelial cells, also in ECM formation (Zhao et al., 2017; Sidgwick and Bayat, 2012). The serum levels of VEGF have been reported to increase considerably in patients with burn wounds (Olsson et al., 2006), and a local rise in the formation of granulation tissue (Infanger et al., 2004). The results of a study by Wu et al. (2006) showed that exogenous VEGF promoted angiogenesis and fibroblast proliferation, and dexamethasone induced keloid regression via suppression of endogenous VEGF expression and fibroblast proliferation. Furthermore, another study revealed VEGF was dynamically correlated with the progression of hypertrophic scar, because the VEGF level was high in early scars, peaked in proliferative scars and decreased in regressive scars (Uchida et al., 2003). Tranilast inhibits the proliferation, migration, tube formation and VEGF-induced chemotaxis in human dermal microvascular endothelial cells (Isaji et al., 1997). In our study, tranilast topical administration significantly decreased VEGF mRNA expression in comparison to the placebo-treated scar group.

The TGF- $\beta$ signaling is believed to be closely associated with wound healing and hypertrophic scarring (Lichtman et al., 2016). Studies using strategies to modify the level of TGF- $\beta$ members during wound healing have revealed that the adult scar-forming mechanism can be altered. Overexpression of TGF- $\beta 1$ and $-\beta 2$ has been found in keloid and keloid-derived fibroblasts (Liu et al., 2012; Xia et al., 2004). The application of neutralizing antibodies against TGF- $\beta 1$ and $-\beta r$ in incisional rat wounds resulted in a significant reduction of ECM deposition and subsequent scarring (Shah et al., 1994). TGF- $\beta$ induces ECM production and remodeling by way of the Smad signaling pathway, as a down-stream mediator of TGF- $\beta$ action (Borena et al., 2015; Leask, 2010). TGF- $\beta 1$ is among the most important stimulators of collagen synthesis, also prevents collagen breakdown (Koese and Waseem, 2008). The major mechanism of the tranilast efficacy appears to be the suppression of the expression and/or action of the TGF- $\beta$ pathway (Darakhshan and Pour, 2015). Tranilast suppresses the release of TGF- $\beta 1$ from fibroblasts (Suzawa et al., 1992a; 
Suzawa et al., 1992b; Platten et al., 2001;) and inhibits TGF- $\beta 1$-induced increase in collagen synthesis by keloid-derived fibroblasts (Suzawa et al., 1992a). Tranilast also involved in Smad phosphorylation and attenuated dramatically the expression of phosphorylated Smad2 (Bonnet et al., 2003; Martin et al., 2005). In our study, topically tranilast-treated skin rats showed a significant decrease in Smad2 mRNA expression compared to the placebo group. Over-expression of Smad7, as an inhibitor of the TGF- $\beta$ actions, may be a potential therapeutic target to improve excessive scarring. Chen and Davidson (2005) showed that over-expression of SMAD7 can significantly decrease excessive cutaneous scar formation. In our study, tranilast increased Smad7 expression and it seems that in this manner caused a reduction in scar formation. From these results, it can be deduced that inhibition of the gene expression of Collagen 1A1 and 3A1, VEGF, TGF $\beta 1$ and Smad2, in parallel to up-regulation of Smad7 by topical tranilast has been effective for the inhibition of hypertrophic scar.

\section{Conclusion}

In this study, topical $0.5 \%$ tranilast gel was shown to improve hypertrophic scar after burn injury in a rat model. However, additional studies in patients with large sample size and long follow-up are needed to determine the role of tranilast topical formulation in hypertrophic scar therapy.

\section{Acknowledgment}

We express our appreciation to Dr. Abbas Piryaei for his technical support.

\section{Conflict of interest}

There is no conflict of interest.

\section{References}

Bonnet F, Cao Z, Cooper ME, Cox AJ, Kelly DJ, Gilbert RE. Tranilast attenuates vascular hypertrophy, matrix accumulation and growth factor overexpression in experimental diabetes. Diabetes Metab 2003; 29: 386-92. https://doi.org/10.1016/S1262-3636(07)70049-6

Borena BM, Martens A, Broeckx SY, Meyer E, Chiers $\mathrm{K}$, Duchateau L, et al. Regenerative skin wound healing in mammals: state-of-the-art on growth factor and stem cell based treatments. Cell Physiol Biochem 2015; 36: 1-23. https://doi.org/10.1159/000374049
Brett EA, Duscher D. Scar treatment and prevention: know thine enemy. In: Regenerative Medicine and plastic surgery. Springer, Cham. 2019, pp. 16-26. https://doi.org/10.1007/9783-030-19962-3_2

Chen MA, Davidson TM. Scar management: prevention and treatment strategies. Curr Opin Otolaryngol Head Neck Surg 2005; 13: 242-7. https://doi.org/10.1097/01. moo.0000170525.74264.f8

Cuttle L, Kempf M, Phillips GE, Mill J, Hayes MT, Fraser JF, et al. A porcine deep dermal partial thickness burn model with hypertrophic scarring. Burns 2006; 32: 806-20. https:// doi.org/10.1016/j.burns.2006.02.023

Darakhshan S, Pour AB. Tranilast: a review of its therapeutic applications. Pharmacol Res 2015; 91: 15-28. https://doi. org/10.1016/j.phrs.2014.10.009

Goto Y, Tsuchiya O, Nishiyama M, Suzawa H, Miyata H. Studies on the metabolic fate of tranilast in rats and mice. $\mathrm{J}$ Clin Report 1991; 25: 69-74.

Infanger M, Schmidt O, Kossmehl P, Grad S, Ertel W, Grimm D. Vascular endothelial growth factor serum level is strongly enhanced after burn injury and correlated with local and general tissue edema. Burns 2004; 30: 305-11. https://doi. org/10.1016/j.burns.2003.12.006

Isaji M, Miyata $\mathrm{H}$, Ajisawa $\mathrm{Y}$, Takehana $\mathrm{Y}$, Yoshimura N. Tranilast inhibits the proliferation, chemotaxis and tube formation of human microvascular endothelial cells in vitro and angiogenesis in vivo. Br J Pharmacol 1997; 122: 1061-6. https://doi.org/10.1038/sj.bjp.0701493

Khiljee S, Rehman N, Sarfraz M, Montazeri H, Lbenberg $\mathrm{R}$, Khiljee T. In vitro release of indian penny wort, walnut, and turmeric from topical preparations using two different types of membranes. Dissolufion Technol 2010; 17: 27-32. https://doi.org/10.14227/DT170410P27

Koese O, Waseem A. Keloids and hypertrophic scars: are they two different sides of the same coin? Dermatol Surg 2008; 34: 336-46. https://doi.org/10.1111/j.15244725.2007.34067.x

Kogure F, Ishizaki M, Saiga T. Long-term clinical study of tranilast ophthalmic solution on vernal conjunctivitis. J Clin Ther Med 1993; 9: 429-41.

Kohavi L, Sprecher E, Zur E, Artzi O. The effect of tranilast $8 \%$ liposomal gel versus placebo on post-cesarean surgical scars: a prospective double-blind split-scar study. Dermatol Surg 2017; 43: 1157-63. https://doi.org/10.1097/ DSS.0000000000001140

Leask A. Potential therapeutic targets for cardiac fibrosis: TGF $\beta$, angiotensin, endothelin, CCN2, and PDGF, partners in 
fibroblast activation. Circ Res 2010; 106: 1675-80. https://doi. org/10.1161/CIRCRESAHA.110.217737

Lichtman MK, Otero-Vinas M, Falanga V. Transforming growth factor beta (TGF- $\beta$ ) isoforms in wound healing and fibrosis. Wound Repair Regen 2016; 24: 215-22. https://doi. org/10.1111/wrr.12398

Liu Z, Lu CL, Cui LP, Hu YL, Yu Q, Jiang Y, et al. MicroRNA-146a modulates TGF- $\beta 1$-induced phenotypic differentiation in human dermal fibroblasts by targeting SMAD4. Arch Dermatol Res 2012; 304: 195-202. https://doi.org/10.1007/ s00403-011-1178-0

Marshall CD, Hu MS, Leavitt T, Barnes LA, Lorenz HP, Longaker MT. Cutaneous scarring: basic science, current treatments, and future directions. Adv Skin Wound Care 2018; 7: 29-45. https://doi.org/10.1089/wound.2016.0696

Martin D, Umraw N, Gomez M, Cartotto R. Changes in subjective vs objective burn scar assessment over time: does the patient agree with what we think? J Burn care rehabilitation 2003; 24: 239-44. https://doi.org/10.1097/01. BCR.0000075842.55039.03

Martin J, Kelly DJ, Mifsud SA, Zhang Y, Cox AJ, See F, et al. Tranilast attenuates cardiac matrix deposition in experimental diabetes: role of transforming growth factor- $\beta$. Cardiovasc Res 2005; 65: 694-701. https://doi.org/10.1016/j.cardiores.2004.10.041

Monstrey S, Hoeksema H, Verbelen J, Pirayesh A, Blondeel P. Assessment of burn depth and burn wound healing potential. Burns 2008; 34: 761-9. https://doi.org/10.1016/j. burns.2008.01.009

Nicholas MN, Yeung J. Current status and future of skin substitutes for chronic wound healing. J Cutan Med Surg 2017; 21: 23-30. https://doi.org/10.1177/1203475416664037

Olsson AK, Dimberg A, Kreuger J, Claesson-Welsh L. VEGF receptor signalling? In control of vascular function. Nat Rev Mol Cell Biol 2006; 7: 359-71. https://doi.org/10.1038/ nrm1911

Platten M, Wick W, Wischhusen J, Weller M. N-[3, 4-dimethoxycinnamoyl]-anthranilic acid (tranilast) suppresses microglial inducible nitric oxide synthase (iNOS) expression and activity induced by interferon- $\gamma($ IFN- $\gamma$ ). Br J Pharmacol 2001; 134: 1279-84. https://doi.org/10.1038/sj.bjp.0704373

Sato H, Fujimori M, Suzuki H, Kadota K, Shirakawa Y, Onoue $\mathrm{S}$, et al. Absorption improvement of tranilast by forming highly soluble nano-size composite structures associated with $\alpha$-glucosyl rutin via spray drying. Eur J Pharm Biopharm 2015; 92: 49-55. https://doi.org/10.1016/j.ejpb.2015.02.021

Shah M, Foreman DM, Ferguson MW. Neutralising anti- body to TGF-beta 1, 2 reduces cutaneous scarring in adult rodents. J Cell Sci 1994; 107: 1137-57. https://doi.org/10.1242/ jcs.107.5.1137

Shpichka A, Butnaru D, Bezrukov EA, Sukhanov RB, Atala A, Burdukovskii V, et al. Skin tissue regeneration for burn injury. Stem Cell Res Ther 2019; 10: 94. https://doi. org/10.1186/s13287-019-1203-3

Sidgwick GP, Bayat A. Extracellular matrix molecules implicated in hypertrophic and keloid scarring. J Eur Acad Dermatol Venereol 2012; 26: 141-52. https://doi.org/10.1111/ j.1468-3083.2011.04200.x

Suzawa H, Kikuchi S, Arai N, Koda A. The mechanism involved in the inhibitory action of tranilast on collagen biosynthesis of keloid fibroblasts. Jpn J Pharmacol 1992a; 60: 91-6. https://doi.org/10.1016/S0021-5198(19)32429-1

Suzawa H, Kikuchi S, Ichikawa K, Koda A. Inhibitory action of tranilast, an anti-allergic drug, on the release of cytokines and PGE2 from human monocytes-macrophages. Jpn J Pharmacol 1992b; 60: 85-90. https://doi.org/10.1016/S00215198(19)32428-X

Uchida G, Yoshimura K, Kitano Y, Okazaki M, Harii K. Tretinoin reverses upregulation of matrix metalloproteinase-13 in human keloid-derived fibroblasts. Exp Dermatol 2003; 12: 35-42. https://doi.org/10.1034/j.1600-0625.12. s2.6.x

Unahabhokha T, Sucontphunt A, Nimmannit U, Chanvorachote P, Yongsanguanchai N, Pongrakhananon V. Molecular signalings in keloid disease and current therapeutic approaches from natural based compounds. Pharmace Biol 2015; 53: 457 63. https://doi.org/10.3109/13880209.2014.918157

Van Loey NE, Bremer M, Faber AW, Middelkoop E, Nieuwenhuis MK, Research Group. Itching following burns: epidemiology and predictors. Br J Dermatol 2008; 158: 95 100.

Vanti G, Wang M, Bergonzi MC, Zhidong L, Bilia AR. Hydroxypropyl methylcellulose hydrogel of berberine chloride-loaded escinosomes: Dermal absorption and biocompatibility. Int J Biol Macromol 2020; 164: 232-41. https://doi. org/10.1016/j.ijbiomac.2020.07.129

Widgerow AD, Chait LA. Scar management practice and science: a comprehensive approach to controlling scar tissue and avoiding hypertrophic scarring. Adv Skin Wound Care 2011; 24: 555-61. https://doi.org/10.1097/01. ASW.0000408465.81257.46

Wu WS, Wang FS, Yang KD, Huang CC, Kuo YR. Dexamethasone induction of keloid regression through effective suppression of VEGF expression and keloid fibroblast pro- 
liferation. J Invest Dermatol 2006; 126: 1264-71. https://doi. org/10.1038/sj.jid.5700274

Xia W, Phan TT, Lim IJ, Longaker MT, Yang GP. Complex epithelial-mesenchymal interactions modulate transforming growth factor- $\beta$ expression in keloid-derived cells. Wound Repair Regen 2004; 12: 546-56. https://doi.org/10.1111/ j.1067-1927.2004.012507.x

Yang L, Shao Y, Han HK. Preparation and in vitro/in vivo characterization of tranilast-AMP clay complex for improving drug dissolution and bioavailability. Arch Pharm
Res 2014; 37: 1554-9. https://doi.org/10.1007/s12272-0140458-6

Zhang H, Yu LX. Dissolution testing for solid oral drug products: theoretical considerations. Am Pharm Rev 2004; 7 : 26-31.

Zhao D, Wang Y, Du C, Shan S, Zhang Y, Du Z, et al. Honokiol alleviates hypertrophic scar by targeting transforming growth factor- $\beta / \mathrm{Smad} 2 / 3$ signaling pathway. Front Pharmacol 2017; 8: 206. https://doi.org/10.3389/fphar.2017.00206 